\title{
Número de policromatófilos na diferenciação das anemias não regenerativas de regenerativas em cães
}

\section{Polycromatophilic cell count in differentiation of non regenerative anemia from regenerative anemia in dogs}

\author{
Nina da Cunha Medeiros ${ }^{1 *}$; Rosangela Locatelli Dittrich ${ }^{2}$
}

\begin{abstract}
Resumo
O método de quantificação de eritrócitos policromatófilos é utilizado na rotina dos laboratórios clínicos veterinários para identificar a resposta da medula óssea. Entretanto, não há padronização desse método em relação ao número absoluto de reticulócitos. No presente estudo foram avaliadas amostras sanguíneas de 135 cães anêmicos e de 21 cães saudáveis de um total de 1875 cães atendidos no Hospital Veterinário da Universidade Federal do Paraná, entre o período de 01 de julho de 2011 a 18 de outubro de 2012. Foram realizados hemogramas e quantificações de eritrócitos policromatófilos e reticulócitos. Os valores de policromatófilos por campo e a contagem absoluta de reticulócitos foram comparados por análises estatísticas para determinar se há correlação entre os dois métodos. Os valores da sensibilidade, especificidade, acurácia e teste Kappa do número de policromatófilos foram, respectivamente, de $86,11 \%, 87,5 \%, 87,12 \%$ e $71 \%$. O coeficiente de correlação de Pearson (r) foi de 0,8125 e o coeficiente de determinação da equação $\left(\mathrm{R}^{2}\right)$ foi de 0,6603 , entre o número de policromatófilos e de reticulócitos. A presença de dois policromatófilos por campo diferenciou a anemia não regenerativa da regenerativa, mas não foi possível associar o número de reticulócitos ao número de policromatófilos e nem classificar a anemia quanto à intensidade de regeneração.
\end{abstract}

Palavras-chave: Resposta medular, anemia, cães, policromatofilia, reticulócitos

\begin{abstract}
The method of quantitation of polychromatophilic cell is routinely used in veterinary clinical laboratories to identify the bone marrow response. However, there is no standardization of this approach over the absolute reticulocyte count. The present study evaluated blood samples from 135 anemic dogs and 21 healthy dogs. CBC and quantification of reticulocytes and polychromatophilic cell were performed. The sensitivity, specificity, accuracy and Kappa of the polychromatophilic cell count were, respectively, $86.11 \%, 87.5 \%, 87.12 \%$ and $71 \%$. The Pearson correlation coefficient (r) was 0.8125 and the coefficient of determination equation (R2) was 0.6603 , between the number of polychromatophilic cell and reticulocytes. The identification of two polychromatophilic cells per field could allow a differentiation between regenerative and nonregenerative anemia, but it was not possible to associate it to the absolute reticulocyte count and classify the intensity of regeneration of anemia.
\end{abstract}

Key words: Bone marrow response, anemia, dogs, polychromatophilic cell, reticulocytes

\footnotetext{
${ }^{1}$ Médica Veterinária Autônoma, Curitiba, PR. E-mail: ninadcm85@gmail.com

${ }^{2}$ Prof $^{\mathrm{a}}$ Associada I, Universidade Federal do Paraná, UFPR, Curitiba, PR. E-mail: roslocdi@ufpr.br

* Autor para correspondência
} 


\section{Introdução}

As anemias ocorrem com grande frequência na rotina clínica de pequenos animais. As principais causas de anemias são as hemorragias agudas, hemólise intravascular, doenças crônicas, insuficiência renal, neoplasias, processos inflamatórios, deficiência nutricional de ferro e doenças da medula óssea (THRALL, 2007). Independente da origem, os parâmetros hematológicos utilizados para diagnosticar e avaliar sua severidade são o hematócrito (Ht), a contagem de eritrócitos totais, concentração de hemoglobina e alterações morfológicas dos eritrócitos. É importante classificar o estado anêmico para determinar a sua origem e avaliar o prognóstico do paciente (MEYER; HARVEY, 2004). O volume globular médio (VGM) e a concentração de hemoglobina globular média (CHGM) são utilizados para classificar a anemia, mas a resposta da medula óssea é mais importante no diagnóstico e prognóstico (COWGILL, 2003; TVEDTEN, 2010).

Em anemias regenerativas, a medula óssea aumenta a produção eritrocitária e a liberação de eritrócitos imaturos. Em casos de anemias não regenerativas a medula óssea é incapaz de responder ao estado anêmico e as células jovens não são liberadas na circulação (THRALL; WEISER, 2006). Uma das formas de avaliar se a medula óssea está respondendo é pela contagem de reticulócitos. O reticulócito é um estágio de maturação das células eritróides que na coloração com corante supravital tem precipitações de RNA ribossomal, denominados retículos. Quando corados com corantes do tipo Romanowsky, devido à presença de hemoglobina, ribossomos e polirribossomos, os reticulócitos apresentam coloração vermelho azulada e são denominados policromatófilos (HARVEY, 2001a).

$\mathrm{Na}$ medicina, a citometria de fluxo tem possibilitado monitorar as anemias por avaliações de subpopulações de reticulócitos e frações de reticulócitos imaturos (JOÃO; PINTO; COSTA, 2008). Na medicina veterinária, a citometria de fluxo é utilizada na contagem de reticulócitos de cães em alguns estudos, mas esta não é a realidade brasileira (PEREIRA etal., 2008; HODGES; CHRISTOPHER, 2011; COLLICUTT; NEEL; GRINDEM, 2012).

$\mathrm{Na}$ rotina dos laboratórios veterinários brasileiros, utiliza-se a contagem manual sob microscopia de luz, técnica que continua sendo o padrão ouro por não sofrer interferências pela presença de eritrócitos nucleados, hemoparasitas, corpúsculos de Howell Jolly e células leucêmicas (COWGILL; NEEL; GRINDEM, 2003; TVEDTEN, 2011).

A avaliação dos policromatófilos é utilizada pelos veterinários, entretanto, não existe uma padronização do método. A quantificação pode ser representada por cruzes $(+)$, por campo, em porcentagem ou por análise subjetiva que classifica como ausente, leve, moderada ou intensa (HARVEY, 2001b; FELDMAN; SINK, 2006; HODGES; CHRISTOPHER, 2011; COLLICUTT; NEEL; GRINDEM, 2012). Apesar de não haver uma padronização e consenso na literatura, a avaliação quanto à resposta da medula óssea no estado anêmico é realizada pelos clínicos pela observação de achados como policromatofilia, presença de metarrubrócitos, anisocitose e presença de corpúsculos Howell Jolly.

O presente trabalho objetivou estabelecer a associação entre o número de policromatófilos e de reticulócitos para a classificação das anemias quanto à resposta da medula óssea.

\section{Material e Métodos}

No presente estudo foram utilizadas amostras de sangue provenientes da rotina clínica do Laboratório de Patologia Clínica Veterinária da Universidade Federal do Paraná. Foram realizados hemogramas e contagens de reticulócitos em amostras de sangue de 135 cães anêmicos (hematócrito $\leq 35 \%$ ) e de 21 cães saudáveis (avaliados pelo histórico, exame físico e exames laboratoriais) (FARVER, 2008). As coletas sanguíneas foram realizadas entre o período de 01 de julho de 2011 a 18 de outubro de 2012 
com os animais submetidos à contenção física. Em seguida as amostras acondicionadas em tubos com EDTA. As contagens de eritrócitos, plaquetas, leucócitos e concentração de hemoglobina foram realizadas em contador automático de células sanguíneas da marca Mindray ${ }^{\circledR}$ modelo BC 2800 VET. O volume globular médio (VGM) e a concentração de hemoglobina globular média (CHGM) foram obtidos pelas fórmulas de Wintrobe (THRALL; WEISSER, 2006). As extensões sanguíneas foram realizadas imediatamente após a coleta sanguínea e coradas com panótico rápido. Nas extensões sanguíneas coradas foram realizadas a contagem diferencial de leucócitos, avaliação da morfologia de eritrócitos e leucócitos e estimativa de número de policromatófilos. Para a estimativa de eritrócitos policromatofílicos, foi realizada a contagem em objetiva de imersão do número médio de policromatófilos por campo, através da contagem em 10 campos homogêneos na franja de cada esfregaço sanguíneo. O campo foi considerado homogêneo quando não havia sobreposição de células e as mesmas se dispunham uma ao lado da outra sem a presença de espaços vazios. As contagens de reticulócitos foram realizadas por técnica manual em microscopia ótica. Volumes iguais $(150 \mu \mathrm{L})$ de sangue total e azul de cresil brilhante foram homogeneizados em tubo de ensaio e mantidos em banho maria a $37^{\circ} \mathrm{C}$ durante 15 minutos. Após este período, foram confeccionadas duas extensões sanguíneas. Depois de secas, as lâminas foram contra coradas com corante de Wright para facilitar a visualização dos retículos. A determinação do percentual de reticulócitos foi realizada por contagem de 1.000 eritrócitos consecutivos. Somente reticulócitos agregados foram considerados na contagem (TVEDTEN; MORITZ, 2010). A contagem absoluta de reticulócitos foi obtida por multiplicação do percentual de reticulócitos pela contagem de eritrócitos, para correção do aumento relativo de reticulócitos nos cães anêmicos.

As anemias foram classificadas como não regenerativas $(<70.000$ reticulócitos $/ \mu \mathrm{L})$, pouco regenerativas (entre 70.000 e 150.000 reticulócitos/ $\mu \mathrm{L}$ ), moderadamente regenerativas (entre 150.000 e 300.000 reticulócitos $/ \mu \mathrm{L}$ ) e muito regenerativas (> 300.000 reticulócitos $/ \mu \mathrm{L}$ ) (COWGILL; NEEL; GRINDEM, 2003; RIZZI; MEINKOTH; CLINKENBEARD, 2010; TVEDTEN, 2010). Para o cálculo da sensibilidade, especificidade, acurácia e teste Kappa da avaliação da resposta da medula óssea pela policromatofilia, anemias com mais de dois policromatófilos por campo foram classificadas como regenerativas (OIE, 2000; HARVEY, 2001b).

Os valores de policromatófilos por campo e a contagem absoluta de reticulócitos foram comparados por análise estatística no programa Graph Pad.Prism 6. A análise de regressão linear e teste de Correlação de Pearson foram realizados para determinar a correlação ou não entre duas variáveis.

\section{Resultados e Discussão}

De acordo com a contagem de reticulócitos, as anemias não regenerativas foram constatadas em $68 \%(92 / 135)$ dos cães e as regenerativas em $32 \%(43 / 135)$. Das anemias regenerativas, 60,5\% (26/43) eram pouco regenerativas, 32,5\% (14/43) eram moderadamente regenerativas e $7 \%(3 / 43)$ eram muito regenerativas. No grupo controle (21 cães saudáveis) a média foi de 13.413 reticulócitos/ $\mu \mathrm{L}$ e de 0 a raros $(<1)$ policromatófilos por campo. A policromatofilia foi avaliada por campo por ser um método quantitativo e por ser comumente empregado na rotina clínica.

$\mathrm{Na}$ tabela 1 estão apresentados os valores de policromatófilos e reticulócitos obtidos no presente estudo. O coeficiente de correlação de Pearson (r) e o coeficiente de determinação da equação $\left(\mathrm{R}^{2}\right)$ entre o número de policromatófilos por campo e a contagem absoluta de reticulócitos foram respectivamente de 0,8125 e 0,6603 (Figura 1). 
Tabela 1. Associação entre valores mínimos e máximos de policromatófilos e reticulócitos em cães apresentando diferentes respostas da medula óssea.

\begin{tabular}{ccccc}
\hline & $\begin{array}{c}\text { Não } \\
\text { Regenerativa }\end{array}$ & $\begin{array}{c}\text { Pouco } \\
\text { regenerativa }\end{array}$ & $\begin{array}{c}\text { Moderadamente } \\
\text { Regenerativa }\end{array}$ & $\begin{array}{c}\text { Muito } \\
\text { Regenerativa }\end{array}$ \\
\hline $\begin{array}{c}\text { Policromatófilos (/C) } \\
\text { Reticulócitos }(/ \boldsymbol{\mu L})\end{array}$ & 0 a 1 & 0,5 a 3,0 & 1,5 a 4,5 & 3,5 a 15 \\
\hline
\end{tabular}

*Classificação da anemia: (COWGILL; NEEL; GRINDEM, 2003; RIZZI; MEINKOTH; CLINKENBEARD, 2010; TVEDTEN, 2010).

Fonte: Elaboração dos autores.

Figura 1. Regressão linear simples entre número de reticulócitos $(/ \mu \mathrm{L})$ e policromatófilos por campo (objetiva de 100X) em cães anêmicos.

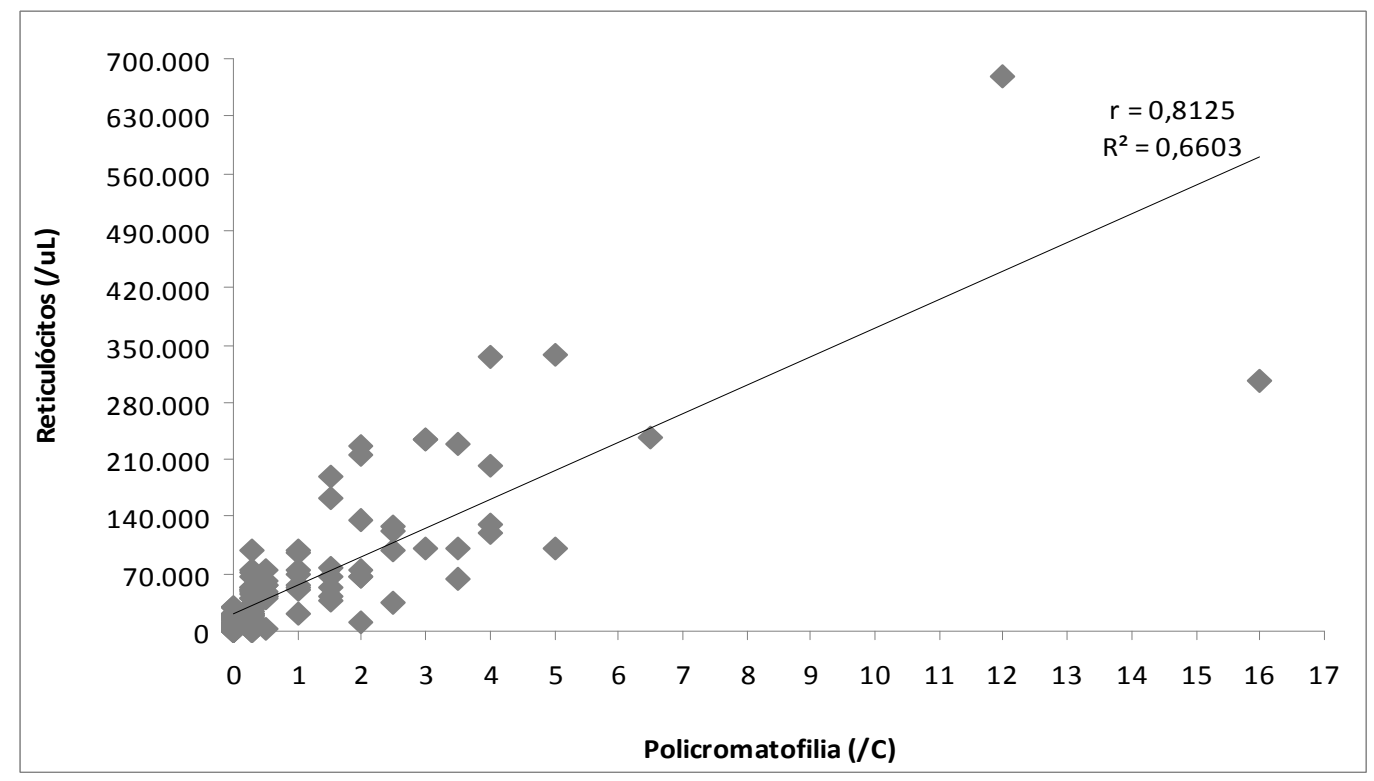

$\mathrm{R}^{2}=$ coeficiente de determinação da equação; $\mathrm{r}=$ coeficiente de correlação de Pearson.

Fonte: Elaboração dos autores.

A associação entre policromatofilia e número de reticulócitos foi significativa considerandose o coeficiente de correlação de Pearson de 0,8125. Os dois métodos não apresentaram uma linearidade perfeita e não foi possível associar com exatidão o número de reticulócitos pelo número de policromatófilos por campo $\left(\mathrm{R}^{2}\right.$ de 0,6603). No grupo de cães com anemia pouco regenerativa, o intervalo da policromatofilia variou de 0,5 (raros) a 3 por campo. Nos animais com anemia moderadamente regenerativa o valor mínimo encontrado foi de 1,5 policromatófilos por campo. Ou seja, se o único parâmetro utilizado for o número de policromatófilos, a resposta da medula óssea será avaliada de maneira equivocada, pois 1,5 policromatófilos por campo pode tanto representar uma anemia pouco regenerativa como moderadamente regenerativa. Esta falta de linearidade ocorre provavelmente porque alguns reticulócitos não têm coloração policromatofílica devido à variação da quantidade dos retículos (THRALL, 2007).

Na medicina veterinária não há uma classificação dos graus de maturação do reticulócito e uma padronização dos graus de maturação para considerar como um reticulócito (RILEY et al., 2001). Em cães anêmicos existem poucos eritrócitos maduros 
na circulação causando um aumento relativo na quantidade de reticulócitos e conseqüentemente na quantidade de policromatófilos. Para anular este aumento relativo, Collicutt, Neel e Grindem (2012) realizaram estudo retrospectivo em 30 cães saudáveis e 60 cães anêmicos, comparando o número absoluto de reticulócitos e de policromatófilos. Obtiveram uma correlação de Pearson de 0,98, superior a encontrada no presente estudo ( $\mathrm{r}$ $=0,8125$ ). Entretanto, a contagem absoluta de policromatófilos exige tanto tempo e conhecimento quanto a contagem absoluta de reticulócitos e não é um método utilizado rotineiramente por exigir prática do executor.

A sensibilidade do método de policromatofilia por campo foi de 86,11\%, especificidade de $87,5 \%$, acurácia de $87,12 \%$ e Kappa de $71 \%$. Ou seja, o método de avaliação pela policromatofilia pode diagnosticar a ausência de regeneração em cães com anemia não regenerativa e a presença de regeneração em cães com anemia regenerativa. Hodges e Christopher (2011) verificaram a acurácia do uso da policromatofilia para identificar anemias regenerativas em cães, obtendo valores de $89 \%$ de sensibilidade, $71 \%$ de especificidade e $77 \%$ de acurácia. A diferença entre valores da acurácia pode ser devido a diferenças de metodologia e no número de amostras analisadas, pois estes autores realizaram a contagem de reticulócitos utilizando citometria de fluxo, método que pode sofrer mais interferências do que a contagem manual sob microscopia de luz (COWGILL; NEEL; GRINDEM, 2003).

\section{Conclusão}

Acontagem de policromatófilos é uma ferramenta diagnóstica de grande acurácia para diferenciar anemias não regenerativas de regenerativas utilizando o valor de dois policromatófilos por campo como ponto de corte. Porém, não é possível associar o número de reticulócitos e classificar a anemia quanto a intensidade de regeneração utilizando este método.

\section{Agradecimentos}

Agradecemos a todos os médicos veterinários, funcionários e residentes do Hospital Veterinário da Universidade Federal do Paraná por colaborarem com a pesquisa.

\section{Comitê de Ética e Biossegurança}

O presente trabalho foi aprovado pelo comitê de Ética no Uso de Animais do Setor de Ciências Agrárias (CEUA-SCA) da Universidade Federal do Paraná. Protocolo número 009/2012.

\section{Referências}

COLLICUTT, N. B.; NEEL, J. A.; GRINDEM, C. D. Comparison of manual polychromatophilic cell and automated reticulocyte quantification in evaluating regenerative response in anemic dogs. Veterinary Clinical Pathology, Madison, v. 41, n. 2, p. 256-260, 2012.

COWGILL, E. S.; NEEL, J. A.; GRINDEM, C. D. Clinical application of reticulocyte counts in dogs and cats. The Veterinary Clinics-Small Animal Practice, Philadelphia, v. 33, n. 1, p. 1223-1244, 2003.

FARVER, T. B. Concepts of normality in clinical biochemistry. In: KANEKO, J. J.; HARVEY, J. W.; BRUSS, M. L. Clinical biochemistry of domestic animal. $6^{\text {th }}$ ed. Missouri: Saunders, 2008. p. 1-25.

FELDMAN, B. F.; SINK, C. A. Eritrócitos. In: Urinálise e hematologia. São Paulo: Roca, 2006. p. 7596.

HARVEY, J. W. Erythrocytes. In: . Atlas of veterinary hematology. Philadelphia: Saunders Company, 2001a. p. 21-44.

Examination of blood samples. In:

Atlas of veterinary hematology. Philadelphia: Saunders Company, 2001b. p. 3-20.

HODGES J.; CHRISTOPHER, M. M. Diagnostic accuracy of using erythrocyte índices and polychromasia to identify regenerative anemia in dogs. Journal of the American Veterinary Medical Association, New York, v. 238, n. 11, p. 1452-1458, 2011. 
JOÃO, A. R.; PINTO, S.; COSTA, E. Subpopulações dos reticulócitos e fração de reticulócitos imaturos como indicadores de aumento da eritropoese em doentes com anemia por deficiência de ferro. Revista Brasileira de Hematologia e Hemoterapia, São José do Rio Preto, v. 30, n. 3, p. 188-192, 2008.

MEYER D. J.; HARVEY, J. W. Evaluation of erythrocytic disorders. In: . Veterinary laboratory medicine. $3^{\text {th }}$ ed. Philadelphia: Elsevier, 2004. p. 47-81.

OFFICE INTERNATIONAL DES EPIZOOTIES OIE. Principles of validation of diagnostic assays for infectious diseases. Vienna: Manual of Standards, 2000. cap. 3, p. 15-23.

PEREIRA, P. M.; SEKI, M. C.; PALMA, P. V. B.; MORAES, F. R.; SANTANA, A. E.; PEREIRA, G. T. Contagem de reticulócitos de cães saudáveis ou anêmicos por citometria de fluxo. Arquivo Brasileiro de Medicina Veterinária e Zootecnia, Belo Horizonte, v. 59, n. 1, p. 66-70, 2008.

RILEY, R. S.; BEN-EZRA, J. M.; GOEL, R.; TIDWELL, A. Reticulocytes and reticulocyte enumeration. Journal of Clinical Laboratoy Analysis, New Jersey, v. 15, n. 1, p. 267-294, 2001.
RIZZI, T. E.; MEINKOTH, J. H.; CLINKENBEARD, K. D. Normal hematology of the dog. In: WEISS, D. J.; WARDROP, K. J. Schalm's veterinary hematology. $6^{\text {th }} \mathrm{ed}$. Iowa: Blackwell Publishing, 2010. p. 799-810.

THRALL, M. A.; WEISER, M. G. Hematologia. In: HENDRIX, C. M. Procedimentos laboratoriais para técnicos veterinários. 4. ed. São Paulo: Roca, 2006. p. 31-78.

THRALL, M. A. Morfologia das hemácias. In: THRALL, M. A.; BAKER, D. C.; DeNICOLA, D.; FETTMAN, M. J.; LASSEN, E. D.; REBAR, A.; WEISER, G. Hematologia e bioquímica clínica veterinária. São Paulo: Editora Roca, 2007. p. 65-77.

TVEDTEN, H.; MORITZ, A. Reticulocyte and heinz body staining and enumeration. In: WEISS, D. J.; WARDROP, K. J. Schalm's veterinary hematology. $6^{\text {th }} \mathrm{ed}$. Iowa: Blackwell Publishing, 2010. p. 1067-1073.

TVEDTEN, H. Laboratory and clinical diagnosis of anemia. In: WEISS, D. J.; WARDROP, K. J. Schalm's veterinary hematology. $6^{\text {th }}$ ed. Iowa: Blackwell Publishing, 2010. p. 152-161.

. What is your diagnosis? Discrepancy between sysmex XT-2000iV reticulocyte count and polychromasia. Veterinary Clinical Pathology, Madison, v. 40, n. 2, p. 275-276, 2011. 